\title{
THE
}

\section{Adaptive management of animal populations with significant unknowns and uncertainties: a case study}

Brian D. Gerber

University of Rhode Island, bgerber@uri.edu

William L. Kendall

Follow this and additional works at: https://digitalcommons.uri.edu/nrs_facpubs

The University of Rhode Island Faculty have made this article openly available.

Please let us know how Open Access to this research benefits you.

This is a pre-publication author manuscript of the final, published article.

Terms of Use

This article is made available under the terms and conditions applicable towards Open Access

Policy Articles, as set forth in our Terms of Use.

Citation/Publisher Attribution

Gerber, B. D. and Kendall, W. L. (2018), Adaptive management of animal populations with significant unknowns and uncertainties: a case study. Ecol Appl, 28: 1325-1341. doi: 10.1002/eap.1734

Available at: http://dx.doi.org/10.1002/eap.1734

This Article is brought to you for free and open access by the Natural Resources Science at DigitalCommons@URI. It has been accepted for inclusion in Natural Resources Science Faculty Publications by an authorized administrator of DigitalCommons@URI. For more information, please contact digitalcommons-group@uri.edu. 
1 Adaptive management of animal populations with significant un-

\section{knowns and uncertainties: a case study}

\section{Brian D. Gerber ${ }^{1,2 *}$ and William L. Kendall ${ }^{3}$}

${ }^{1}$ Colorado Cooperative Fish and Wildlife Research Unit, Department of Fish, Wildlife, and Conservation Biology, Colorado State University, Fort Collins, CO 80523-1484, USA.

${ }^{2}$ Department of Natural Resources Science, University of Rhode Island, Kingston, RI 028812018, USA.

${ }^{3}$ U.S. Geological Survey, Colorado Cooperative Fish and Wildlife Research Unit, Department of Fish, Wildlife, and Conservation Biology, Colorado State University, Fort Collins, CO 80523-1484, USA.

*Corresponding Author: Brian D. Gerber, 1 Greenhouse Road, University of Rhode Island, Kingston RI 02881-2018, USA. Phone: 401-874-5836. bgerber@uri.edu.

Running Head: Population decision making

\section{Abstract}

Conservation and management decision making in natural resources is challenging due to numerous uncertainties and unknowns, especially relating to understanding system dynamics. Adaptive resource management (ARM) is a formal process to making logical and transparent recurrent decisions when there are uncertainties about system dynamics. Despite wide recognition and calls for implementing adaptive natural resource management, applications remain limited. More common is a reactive approach to decision making, which ignores future system dynamics. This contrasts with ARM, which anticipates future dynamics of ecological process and management actions using a model-based framework. Practitioners may be reluctant to adopt ARM because of the dearth of comparative evaluations between 
ARM and more common approaches to making decisions. We compared the probability of meeting management objectives when managing a population under both types of decision frameworks, specifically in relation to typical uncertainties and unknowns. We use a population of sandhill cranes as our case study. We evaluate each decision process under varying levels of monitoring and ecological uncertainty, where the true underlying population dynamics followed a stochastic age-structured population model with environmentally driven vital rate density-dependence. We found that the ARM framework outperformed the currently employed reactive decision framework to manage sandhill cranes in meeting the population objective across an array of scenarios. This was even the case when the candidate set of population models contained only naïve representations of the true population process. Under the reactive decision framework, we found little improvement in meeting the population objective even if monitoring uncertainty was eliminated. In contrast, if the population was monitored without error within the ARM framework, the population objective was always maintained, regardless of the population models considered. Contrary to expectation, we found that age-specific optimal harvest decisions are not always necessary to meet a population objective when population dynamics are age-structured. Population managers can decrease risks and gain transparency and flexibility in management by adopting an ARM framework. If population monitoring data has high sampling variation and/or limited empirical knowledge is available for constructing mechanistic population models, ARM model sets should consider a range of mechanistic, descriptive, and predictive model types.

Key-words: adaptive management; decision theory; Markov decision process; optimal decision; population dynamics; population monitoring; population management; sandhill crane; age-structured; stochastic dynamic programming 


\section{Introduction}

Natural resource managers routinely make decisions in the face of many uncertainties (Holling 1978; Kendall 2001; Regan et al. 2002). These decisions are often aimed at manipulating ecological systems, as a means to reach a specific state and/or to extract value from the system (e.g., non-consumptive or consumptive utility; Holling 1978). Ecological system dynamics are highly complex and thus making a decision that will lead to meeting objectives can be complicated (Holling 1978; Kendall 2001). Common sources of uncertainty include understanding of fundamental system processes, the effect of management actions on system processes, and even the current state of the system.

Recurrent decisions add additional complexity because current decisions can affect the future state of the system and thus future decision making (Williams et al. 2007). However, recurrent decision making also enables learning about system processes while managing; learning explicitly decreases uncertainties associated with management, thus improving future decisions (Williams et al. 2007; Williams 2011a). Considering current and future decisions simultaneously with uncertain system dynamics, makes the decision process highly unintuitive and can benefit from a formal optimal decision process (Williams 2011a). The paradigm that outlines the process of making recurrent decisions in the face of uncertainties, with respect to explicit objectives and constraints, is adaptive resource management (ARM; Holling 1978; Walters 1986). ARM aims to recognize multiple types of uncertainties, such as monitoring uncertainty and partial controllability, but is primarily to improve future decisions by reducing uncertainty regarding system dynamics.

ARM is a special case of structured decision making (Williams et al. 2007), which is a general framework for making informed decisions through a logical and transparent process (Gregory et al. 2012; Gerber et al. 2017). ARM's appeal is its evidence-based approach to management (Walker 1998; Sutherland et al. 2004; Westgate et al. 2013). Despite much support for ARM and calls for its implementation (U.S. NABCI Committee 2007; Williams 
et al. 2007; Wilson and Woodraw 2013), operational programs are uncommon (but see, Johnson et al. 1997; McGowan et al. 2015), but likely growing (Gannon et al. 2013; Westgate et al. 2013). One reason for the slow adoption or even resistance to ARM, and model-based decision making in general, could be that managers, stakeholders, and researchers desire explicit demonstrations that compare ARM to current management strategies to better understand realistic expectations (Hall and Fleishman 2010). Theoretical expectations are less meaningful than realistic demonstrations when making decisions about a public or valued resource.

Adaptive management (as well as other model-based dynamic decision approaches) is an anticipatory approach, based on explicit predictions of system responses to management actions. A more common management strategy in natural resource is a reactive one, in which a decision (e.g., sport harvest or area closures due to breeding) is based on the current observed state of the system (e.g., population size) and does not formally evaluate trade-offs between decisions made immediately and those made in the future (Martin et al. 2009). Two common reactive strategies include taking conservation actions if the finite rate of population change $(\lambda)$ is estimated to be less than 1.00 for a threatened animal population, or hunting of a game species is restricted or closed if the population size falls below a population objective threshold. In contrast, ARM takes an anticipatory strategy to balance trade-offs between decisions over some time frame to meet explicit objectives. When certain system states are highly undesirable (e.g., population decline of a threatened species), ARM guides the system away from these by anticipating possible environmental processes or decisions that could lead to them (Martin et al. 2009).

ARM anticipates future system changes through a model-based framework. Hypotheses of system dynamics are explicitly defined and used to anticipate future outcomes under potential management actions and environmental processes. Supporters of ARM often note that making decisions need not be impeded by a lack of consensus about our understanding of system processes (Nichols and Williams 2006; Martin et al. 2009; Marescot et 
al. 2013), because ARM enables learning about the system while managing. ARM naturally incorporates the philosophy of multiple working hypotheses (Chamberlin 1890) and updating the relative belief in hypotheses based on new monitoring information. But to do so meaningfully requires a well-designed monitoring program that estimates appropriate parameters, relevant to management objectives (Nichols and Williams 2006; Kendall and Moore 2012). A logical and unanswered question is whether the likelihood of meeting management objectives is better or worse when making decisions based on a potentially 'poor' set of models and/or monitoring data in an ARM framework, compared to decisions from a non model-based, reactive approach to management. By 'poor', we mean models that are either relatively simple compared to the likely ecological process, due to limited available empirical knowledge, or monitoring data are highly influenced by sampling variability, such that the true state of the system may be observed with error. Both issues are common throughout natural resource management and conservation biology.

Our objective is to evaluate an anticipatory approach to optimal decision making under ARM relative to that of a more common reactive decision strategy in meeting management objectives for wild animal populations. We do so using the example of the Rocky Mountain Population (RMP) of sandhill cranes (Antigone canadensis); the RMP exemplifies a population that is managed reactively, with annual decisions about allowable harvest. Knowledge of RMP population dynamics is sufficient to specify basic population models, but there is a known knowledge gap of vital rate variability and population structure. Moreover, annual population monitoring data is characterized by considerable sampling variability (Gerber and Kendall 2017), such that the true state of the system may be obscured, and there is no current information to correct these observations.

We compare these two decision strategies using a simulation approach, where the true population dynamics are governed by a stochastic age-structured population model with vital rate density-dependence coupled to environmental variability. Common to population management programs, there is an explicit objective for the RMP to maintain a population 
of sandhill cranes within a specific range; the RMP objective is to maintain the population within 17,000 and 21,000. Sport harvest is the primary mechanism for maintaining this objective. We compare the potential for an ARM versus reactive framework to meet this management objective under a variety of scenarios that vary by structural and monitoring uncertainty. Structural uncertainty represents the uncertainty with regard to the true processes governing sandhill crane dynamics (represented by different population models), while monitoring uncertainty is due to error in observations of the true population size, or the agestructure is unknown and has to be assumed. Here, we focus on a situation where there is no information to correct for uncertainty of our observed population size. By comparing scenarios with different types of uncertainty (i.e., structural, monitoring), we can understand the relative value of eliminating one or multiple uncertainties in meeting the population objective. We use as our measure of success the probability of meeting the population objective across different scenarios.

We use harvest of a long-lived, age-structured bird as an example, while our findings will more generally help conservation and management organizations adopt appropriate frameworks for decision making, depending on the state of knowledge of the system and robustness of current monitoring. Results will also clarify the connections among hypotheses, predictive models, monitoring, and the potential for and utility of learning about population dynamics within ARM. Organizations using ARM, are considering adopting ARM, or currently managing populations via a reactive decision process will find our results especially pertinent.

\section{Methods and materials}

\section{Sandhill crane life-history and management}

Sandhill cranes are large, vocal, birds that are admired as an icon throughout North America (Gerber et al. 2014). They are protected and managed in the United States under the Migratory Bird Treaty Act of 1918, which aims to balance the use and conservation of mi- 
gratory bird species. As with many migratory bird species in North America, populations are defined according to breeding area affiliation and managed according to plans outlined by state agencies and the U.S. Fish and Wildlife Service (Pacific Flyway Council and Central Flyway Council 2016). Management objectives vary by population and are based on ecological and societal values, which for most large crane populations, includes sport harvest. Sport harvest provides recreational opportunities and is intended to mitigate agricultural crop damage from cranes, which can be considerable (Gerber et al. 2014). Harvest decisions are made annually and pertain to the entire population throughout their range (Pacific Flyway Council and Central Flyway Council 2016).

Life history characteristics of sandhill cranes include an average clutch size of 1.9 (see Gerber et al. 2014), high annual adult survival (>0.92 Drewien et al. 1995, 2001), and first attempted breeding by 2-3 years of age with most productive birds greater than 7-8 years of age (Drewien et al. 2001; Tacha et al. 1989). Sandhill cranes have the lowest known juvenile recruitment of any sport-harvested bird in North America (Drewien et al. 1995), which for the RMP is driven by climate, such as drought reducing the quality or quantity of breeding wetlands (Gerber et al. 2015).

\section{RMP monitoring and harvest decision making}

The RMP is monitored annually via a fall pre-migratory staging area population survey that started in 1997 and results in an aggregated count $(C)$; the survey is coordinated across federal and state agencies and includes aerial and ground counts throughout the breeding area states (Colorado, Utah, Wyoming, Montana, Idaho; Pacific Flyway Council and Central Flyway Council 2016; Kruse and Dubovsky 2015). There is no additional information collected to adjust $C$ for potential biases: flocks could be missed or double-counted due to survey duration and migration timing, and surveyed flocks could be undercounted due to visibility or counting bias. Moreover, the survey is an attempt at a total count, providing no basis for estimating its variance. Since 1972, an annual recruitment survey has been con- 
ducted to estimate the proportion of juveniles $(<1$ year old $)$ in the population $\left(P_{t}\right)$ during the fall migration, where $>90 \%$ of the population stops over in the San Luis valley (SLV) of south-central Colorado. The current harvest allocation for the entire RMP is based on the following prescriptive function (Pacific Flyway Council and Central Flyway Council 2016),

$$
H_{t}=\mathrm{g}\left(C 3_{t}, P 3_{t}, R, L\right)= \begin{cases}0 & , C 3_{t}<15,000 \\ C 3_{t} \times P 3_{t} \times R \times L \times\left(\frac{C t}{16,000}\right)^{3} & , C 3_{t} \geq 15,000\end{cases}
$$

where $H_{t}$ is the number of hunting permits allocated in year $t, C 3_{t}$ is an index to the population based on smoothing the annual fall pre-migratory population counts $\left(C 3_{t}=\right.$ $\left.\frac{C_{t-3}+C_{t-2}+C_{t-1}}{3}\right), P 3_{t}$ is an index to juvenile production as measured by smoothing the proportion of juveniles in the population $\left(P 3_{t}=\frac{P_{t-3}+P_{t-2}+P_{t-1}}{3}\right), R$ is an estimated recruitment of fledged chicks to breeding adults $(R=0.5)$, and $L$ is an estimated retrieval rate of cranes shot by hunters $(L=0.8$, thus $20 \%$ crippling loss). Population counts and the proportion of juveniles are smoothed to reduce variation caused by poor counts or estimates in any given year. This function is structured to harvest a total number of individuals that is some proportion of the number of juvenile birds in the population, scaling this proportion based on whether the population index is below, within, or above a population threshold. The aim is to maintain the population within the management objective of between $17,000-21,000$ cranes

An increase in either $P 3_{t}$ or $C 3_{t}$ increases allowable number of hunting permits nonlinearly (Appendix S1: Figs. S1 and S2). Between 1997 and 2014, the allowable harvest for the RMP, as determined by function g (Eqn. 1), averaged 1132 (range, 632-1970). This translated into an estimated mean annual realized harvest of 852 (range, 446-1392; Kruse and Dubovsky 2015). Because of generally consistent conditions within the RMP, the allowable harvest has not varied as much as it could, thus leaving questions as to how Eqn. 1 will 
operate under a sizable range of possible future conditions (Appendix S1: Figs. S1 and S2).

\section{Adaptive management framework}

An alternative approach to the RMP's reactive decision framework is an anticipatory ARM framework that uses explicit population models and decision theory to identify the optimal harvest policy to meet long-term management objectives. To evaluate the probability of meeting the management objective under these decision frameworks, we can suppose a sandhill crane population operates according to known demographic processes, specified using a stochastic population model (i.e., defined as the Generating Model throughout), which is being managed under a reactive or ARM decision process. For the ARM framework, managers can specify competing population models that are used for optimal policy identification and learning. To evaluate each decision process, including alternative sets of population models within ARM, we can compare the probability of meeting our long-term management objectives under each framework; in addition, for each type of decision framework, we can compare scenarios with different combinations of structural and monitoring uncertainty, along with a defined decision framework to understand the value of eliminating uncertainties, singularly or in combination.

\section{ARM decision process}

To outline an adaptive management framework for sandhill cranes, we consider multiple competing population models that can predict crane populations in year $t+1$ based on the population in the current year $t$ and a harvest decision $\left(H_{t}\right)$. Competing models represent alternative hypotheses about population dynamics (i.e., due to structural uncertainty). By summarizing these models as a discrete Markov process (i.e., population transitions depend only on the current population state and harvest decision), we can evaluate an optimal statedependent harvest management policy using stochastic dynamic programming (Marescot et al. 2013). In other words, we can calculate the optimal set of harvest decisions for all 
potential total population sizes that will meet our long-term objectives, choosing a specific harvest quota based on the current population size (i.e., current state of the system). Note, that the decision process is in regards to population state transitions (i.e., total population size), while the population dynamics and some population models (described below) are agespecific, referring to specific age-classes that have different relative influence on the dynamics. We outline the six essential elements of our Markov-decision problem (Marescot et al. 2013) by first specifying our objective to follow the RMP management plan (Pacific Flyway Council and Central Flyway Council 2016): to maintain a population between 17,000 and 21,000 in perpetuity. Second, we define a vector of possible states of the population, from 10,000-40,000 cranes at an interval of 500. Third, we define a vector of possible actions as harvest from 0-4000 at an interval of 100. Fourth, we create an array to define the probability of transitioning from the current state $\left(N_{t}\right)$ to a population state in year $t+1\left(N_{t+1}\right)$, based on a harvest decision $\left(H_{t} ; P\left(N_{t+1} \mid N_{t}, H_{t}\right)\right)$. We calculate these transition probabilities by simulating from hypothesized population models (see Population Models and Simulation Setup); the simulated distribution is discretized using the defined possible states. Therefore, for each model we predict the future possible population states under all possible harvest decisions. For each year $t$, we incorporate model uncertainty by assigning model weights, representing the relative belief in the ability of each model to predict crane population dynamics. Model weights are updated with each harvest decision and annual observation of the population by evaluating the discrepancy between the prediction of each model and the observed population (see Learning). We then use a weighted average of the predicted transition probabilities across all models and under alternative harvest decisions, where the weighting is based on each model weight. Fifth, we define the utility function, representing our management/population objective, for each year $t$ (also called a reward function; Eqn. 2) that represents the desirability of a resulting state over time, 


$$
U\left(N_{t}\right)_{t}= \begin{cases}1 & , 17,000 \leq N_{t} \leq 21,000 \\ 0 & , \text { otherwise }\end{cases}
$$

The utility function states that for any year the population meets our objective $(17,000 \leq$ $N_{t} \leq 21,000$ ), we assign a one and if it doesn't, we assign a zero. This allows us to use an optimization process to find the decision that will maximize the number of one's we obtain. Note that we only give utility to the ensuing state of the population and not to the harvest resulting from the action. The sixth element is calculating the optimal policy, which indicates the optimal harvest decision for each possible population state. A decision is optimal when it is expected to best satisfy the objectives over time. Solving stochastic Markov-decision problems can be done using a number of algorithms (Marescot et al. 2013). We use our utility function with our weighted averaged transition probability array, and the vector of possible harvest actions, to derive the optimal policy via dynamic programming using the policy iteration algorithm implemented in the R package 'MDPtoolbox' (Chadès et al. 2013). Because we are interested in sustaining the population in perpetuity, we solve for the optimal policy for an infinite time horizon with virtually no depreciation in the future value of meeting our population objective (i.e., the discount factor was nearly one at 0.9999; the small difference from one was to ensure optimization convergence). Based on the goals of the RMP management plan, there is no justification for discounting future populations.

\section{Learning}

Learning about the relative predictive merit of crane population models occurs by updating model weights sequentially by year. This is done by evaluating the discrepancy between the prediction of each model using the current population state $\left(N_{t}\right)$ and implemented harvest decision $\left(H_{t}\right)$, with that of an observation of the population in the following year $\left(N_{t+1}\right.$; Eqn. 3). The weight of model $i$ is updated using Bayes Theorem, 


$$
P\left(\text { Model }_{i, t+1} \mid N_{t+1}\right)=\frac{P\left(N_{t+1} \mid \text { Model }_{i}\right) \times P\left(\text { Model }_{i, t}\right)}{\sum_{j=1}^{n} P\left(\text { Model }_{j, t}\right) \times P\left(N_{t+1} \mid \text { Model }_{j, t}\right)} .
$$

The $P\left(\right.$ Model $\left._{i, t}\right)$ is the model weight of Model $_{i, t}$ in the previous year and $P\left(N_{t+1} \mid\right.$ Model $\left._{i}\right)$ is the probability density of the observed population size, given the predicted distribution of $N_{t+1}$ under Model $i$. We estimate this probability by assuming that predictions under a given model follow a Normal distribution and use the probability density function to calculate the probability of the observed population size $\left(N_{t+1}\right)$, given the mean and variance of the predicted distribution of Model $i$. We use this approach because it provides a comparable measure across different types of models, which may or may not be fit using likelihood theory. We investigated alternative approaches and found using the Normal distribution straightforward and appropriate because predictive distributions were symmetric and unimodal. This would have not been appropriate if our populations approached zero, but this was not the case. More so, we found using the relative frequency from the predictive distribution led to issues of dropping models from the model set because an observed population size outside the predictive distribution would have a weight of zero. Rather, the Normal distribution allowed a continuous probability density over the entire real number line $(\mathrm{x} \in \mathbb{R})$.

Our approach to learning is passive (Kendall 2001; Williams 2011b), such that the optimization focus is exclusively on meeting our management objective rather than the value of learning; however, learning still occurs, but as a by-product of the iterative decision process. This is in contrast to an active process to learning, where we anticipate the effect of the decision on resolving model uncertainty (Williams 2011b). The learning process is relative (comparative) among models, and therefore conditional on the quality of the model set. If models represent clear hypotheses about the system, updating weights provide a process to shift support for each hypotheses based on new monitoring data. However, it is 
rarely justifiable to assume the model set contains a model that represents the true population dynamics. Thus, an alternative focus on learning would be to identify a model or average model set that provides robust predictions to make decisions that lead to meeting objectives. In contrast, there is no formal learning within the reactive decision process because there is no set of models to compare; learning is more general, such as how the population may change as a response to harvest.

\section{Population Models and Simulation Setup}

\section{Simulation workflow}

To evaluate the reactive and ARM decision frameworks, we outline a simulation process that considers a wide range of potential crane population dynamics. The simulation has three fundamental elements, 1) a Generating Model that produces age-structured population dynamics coupled with environmentally driven vital rate density-dependence based on a stochastic carrying capacity, 2) a monitoring process that determines whether the population in each year can be observed perfectly or with error and whether the age-structure is observed or only the total population size, and 3) a decision process which either uses ARM or the reactive RMP process (Eqn. 1.; Box 1). For both decision frameworks, harvest decisions are made annually for the total population size, which affects the population trajectory from the Generating Model. Therefore, despite age-structured population dynamics, decisions are made without explicit consideration of the age-structure. To incorporate structural uncertainty in ARM, we consider model sets that include all or a subset of six alternative models, which may also include the Generating Model. When only the total population size is observed, an assumption about the age-structure is required to make predictions with age-specific population models. Ignorance of population age-structure is common for many species, as it is often logistically infeasible or cost prohibitive to estimate it directly (Gerber and Kendall 2016). More so, population models either make an assumption about the carrying capacity or do not incorporate it at all. This provides a realistic situation in which 
environmental variation causes density-dependent effects, but we can not accommodate such dynamics because data on carrying capacity is unavailable or unknowable.

\section{The Generating Model}

Representative of a long-lived, age-structured population, we define the 'true' sandhill crane population dynamics to follow a stochastic, density-dependent population model with agestructure. Ages are defined from zero to eight, where the eighth age includes all individuals that are eight or older. Currently available crane data do not support a fully empirical parameterization of such a model. We thus use empirical estimates of sandhill crane vital rates (i.e., survival, fecundity, breeding proportion) coupled with simple functional equations (i.e., non-mechanistic) to define density-dependent processes to capture the general dynamics of a highly age-structured population in a changing environment. Our aim is not to mimic sandhill population dynamics per se, or limit population dynamics to only what has been observed, but to capture a wide range of potential conditions that is feasible for a long-lived vertebrate, including population stability, increase, and decrease, as well as changing agestructure. This approach allows us to fully consider the benefits of each type of decision process.

All vital rates at or near carrying capacity are defined based on empirical findings from the RMP. Survival parameters are age-specific $\left(S_{k}\right.$ for age $\left.k\right)$ and based on estimates from a 23-year mark-resight study (Kendall, W.L., and Drewien, R.C., unpublished data). Fecundity is the average number of young per pair observed over 40 years (Drewien 2011). Only older individuals $\geq 5$ years old can breed, while most production comes from individuals $\geq 8$ years old (Gerber et al. 2014); these individuals have the highest probability of breeding, which declines with younger ages (Drewien, R.C., unpublished data). Realized harvest $\left(f\left(H_{k, t}, N_{k, t}\right)\right.$ for age $k$ and year $\left.t\right)$ is compensated up to natural mortality (i.e., nonharvest mortality determined by the survival parameters; see Appendix S2), as suggested by empirical results (Kendall, W.L., and Drewien, R.C., unpublished data; Gerber and Kendall 
2017); the realized harvest is equal to the annual allocated harvest from the decision process (see Discussion and Appendix S2 for comments on partial controllability).

Vital rates (survival, fecundity, breeding proportion) are assumed to be affected by changing environmental conditions, characterized as the annual carrying capacity $\left(K_{t}\right.$; Fig. 1a; Appendix S2). The carrying capacity represents all the ecological conditions which are needed to support the population and is annually stochastic, to incorporate realistic annual changes in environmental conditions. We consider the carrying capacity to be initially stable and set at the approximate population size of the RMP for the last two decades (20,000; Gerber 2015); it then stochastically increases for several decades and then declines for several decades back to the initial capacity (Fig. 1a; Appendix S2). We do so to consider the performance of each decision framework across a stable, increasing, and declining population. Harvest decisions $(t=21$ to 100) occur over all three environmental epochs to understand potential sensitivities of ARM or the reactive decision process. Functional equations are used to define vital rate density dependence based on theoretical and empirical population processes (Eberhardt 2002), such that vital rates are negatively affected by increasing population size in the following order, 1) juvenile survival, 2) proportion of breeders, 3) reproductive rate, and 4) adult survival. Non-vital rate parameters included in the density-dependent functions listed below are not based on empirical estimates, but are used to merely force this order of how density dependence effects the population dynamics.

Parameters are noted in italic, while density-dependent functions and statistical distributions are not. Density-dependent functions for the proportion of breeding individuals and per capita fecundity are described as $($ PrBreed $=0.25$ and Fecundity $=1.24$; Fig. 1b, $1 c)$

$$
\text { PropBreeding }\left(\operatorname{PrBreed}, N_{t}, K_{t}\right)= \begin{cases}\text { PrBreed } & , N_{t} / K_{t}<4 / 5 \\ \text { PrBreed }+0.16-0.2 \times N_{t} / K_{t} & , \text { otherwise }\end{cases}
$$


and

$$
\text { Fecundity }\left(\text { Fecundity }, N_{t}, K_{t}\right)= \begin{cases}\text { Fecundity } & , N_{t} / K_{t}<1 \\ \text { Fecundity }+0.7-0.7 \times N_{t} / K_{t} & , \text { otherwise }\end{cases}
$$

All survival parameters are stochastic (see Appendix S2). We assumed baseline juvenile survival (1st year, $S_{1, t}$ ) follows a Beta distribution with a mean of 0.73 and variance of 0.07 (Fig. 1d), which is affected by the population size as,

$$
\operatorname{JuvSDD}\left(S_{1, t}, N_{t}, K_{t}\right)= \begin{cases}S_{1, t} & , N_{t} / K_{t}<3 / 4 \\ S_{1, t}-\left(0.7 \times N_{t} / K_{t}\right)^{3} & , \text { otherwise. }\end{cases}
$$

Adult survival $\left(S_{2-8, t}\right)$ is defined similarly, where the mean of $S_{k, t}$ for $k=2$ to 8 is $0.80,0.90$, 0.93, 0.94, 0.95, 0.96, 0.97, respectively, while the variances are 0.06, 0.05, 0.04, 0.03, 0.02, 0.01, 0.01, respectively. An alternative density-dependence function is used, where adult survival is less negatively affected than juvenile survival (Fig. 1d; Eberhardt 2002),

$$
\operatorname{AdultSDD}\left(S_{2-8}, N_{t}, K_{t}\right)= \begin{cases}S_{k, t} & , N_{t} / K_{t}<1.5 \\ S_{k, t}+0.3-\left(0.1 \times N_{t} / K_{t}\right)^{1 / 2} & , \text { otherwise. }\end{cases}
$$

The generating population model is defined following the population size of each age $k$ in year $t\left(N_{k, t}\right)$, the number of breeders $\left(z_{k, t}\right)$, and survival probability $\left(S_{k}\right)$,

$$
\begin{aligned}
& z_{8, t+1} \sim \operatorname{Binom}\left(N_{8, t+1}, \operatorname{PropBreeding}\left(\operatorname{PrBreed}, N_{t}, K_{t}\right)\right) \\
& z_{7, t+1} \sim \operatorname{Binom}\left(N_{7, t+1}, \operatorname{PropBreeding}\left(\operatorname{PrBreed} / 2, N_{t}, K_{t}\right)\right) \\
& z_{6, t+1} \sim \operatorname{Binom}\left(N_{6, t+1}, \operatorname{PropBreeding}\left(\operatorname{PrBreed} / 3, N_{t}, K_{t}\right)\right) \\
& z_{5, t+1} \sim \operatorname{Binom}\left(N_{5, t+1}, \operatorname{PropBreeding}\left(\operatorname{PrBreed} / 5, N_{t}, K_{t}\right)\right)
\end{aligned}
$$




$$
\begin{aligned}
& N_{1, t+1} \sim \operatorname{Poisson}\left(\sum_{i=5}^{8} \frac{\text { Fecundity }\left(\text { Fecundity }, N_{t}, K_{t}\right)}{2} \times z_{i, t+1}\right) \\
& N_{2, t+1} \sim \operatorname{Binom}\left(N_{1, t}, S_{1, t}\right)-\mathrm{f}\left(H_{1, t}, N_{1, t}\right) \\
& N_{3, t+1} \sim \operatorname{Binom}\left(N_{2, t}, S_{2, t}\right)-\mathrm{f}\left(H_{2, t}, N_{2, t}\right) \\
& N_{4, t+1} \sim \operatorname{Binom}\left(N_{3, t}, S_{3, t}\right)-\mathrm{f}\left(H_{3, t}, N_{3, t}\right) \\
& N_{5, t+1} \sim \operatorname{Binom}\left(N_{4, t}, S_{4, t}\right)-\mathrm{f}\left(H_{4, t}, N_{4, t}\right) \\
& N_{6, t+1} \sim \operatorname{Binom}\left(N_{5, t}, S_{5, t}\right)-\mathrm{f}\left(H_{5, t}, N_{5, t}\right) \\
& N_{7, t+1} \sim \operatorname{Binom}\left(N_{6, t}, S_{6, t}\right)-\mathrm{f}\left(H_{6, t}, N_{6, t}\right) \\
& N_{8, t+1} \sim \operatorname{Binom}\left(N_{7, t}, S_{7, t}\right)+\operatorname{Binom}\left(N_{8, t}, S_{8, t}\right)-\mathrm{f}\left(H_{7, t}, N_{7, t}\right)-\mathrm{f}\left(H_{8, t}, N_{8, t}\right) \\
& N_{t+1}=\sum_{\forall k} N_{k, t+1}
\end{aligned}
$$

384

\section{Monitoring uncertainty}

Regardless of the decision process (reactive or ARM), it is common to only observe a count of the population $\left(\right.$ Count $\left._{t}\right)$, rather than the true abundance $\left(N_{t}\right)$. In the below section (Scenarios), we consider simulation scenarios where, in any given year, the population may be over- or under-counted as,

$$
\log \left(\text { Count }_{t}\right) \sim \operatorname{Normal}\left(\log \left(N_{t}\right), 0.07\right),
$$

where the observational variation (0.07) was estimated from the RMP monitoring data (Gerber and Kendall 2017). Thus, in an ARM framework, models predict the population in year $t+1$, and models are updated using the observed Count $t$ rather than the true population size $\left(N_{t}\right)$. As such, the optimal decision process is based on potentially incorrect information. There is no correction within the decision process, such as when using partially observable Markov decision processes, which recognizes the reality that many monitoring programs ob- 
serve data with error and can't account for it. This is the case for RMP sandhill cranes and numerous other migratory birds (Gerber and Kendall 2017). For scenarios where the population is observed with error and the reactive decision process is employed, harvest decision making (Eqn. 1) is done using Count $t_{t}$ instead of $N_{t}$.

\section{ARM Alternative Population Models}

Parameterizing a highly structured population model like the Generating model will not be feasible for most species and populations. Empirical studies and monitoring sources are simply too limited to do so, despite the knowledge that populations are often highly structured (by age or life stage), variable, and vital rates depend on density-dependent relationships. However, within ARM, any model that can predict the future population state, given the current state $\left(N_{t}\right.$, or $\left.C_{t}\right)$ and harvest decision $\left(H_{t}\right)$ could be considered; this includes mechanistic or descriptive models (e.g., regression models), simple or complex models that range in degree of integrated parameters, or purely predictive models that include no representation of processes (e.g., time-series models; Nichols et al. 2001). We consider a variety of common population models to be used to predict future population states within the ARM process. These models are typically considered in research and management. We consider a variety of these model types to balance the strengths and limitations of each to potentially achieve a model set that can provide useful predictions over a wide range of conditions. Within the ARM framework, we considered six different predictive population models. In the below section (Scenarios), we outline simulation scenarios that use different combinations of these six models within an ARM model set, which may or not also include the Generating model. Models incorporating data beyond the monitoring of total population size $\left(N_{t}\right)$ and proportion of juveniles in the population (see Model 2), are not updated within each year of the simulation. As with many wildlife monitoring programs, such as the RMP sandhill cranes, new annual information about the population is limited. Information about vital rate parameters, such as age-specific survival, are assumed to come from a separate study 
that is not part of regular annual monitoring.

\section{Model 1}

Model 1 is an autoregressive time-series model; it incorporates a $1^{\text {st }}$ order Markov process, where the population in year $t+1\left(N_{t+1}\right)$ depends on an intercept $\beta_{0}$, the autocorrelation parameter $\rho$, the previous year's population $\left(N_{t}\right.$, which may be observed with error, depending on the scenario), the number of birds harvested $\left(H_{t}\right)$, and noise $(\epsilon)$, which has a mean of zero and variance of $\sigma^{2}$,

$$
\begin{aligned}
N_{t+1} & =\beta_{0}+\rho \times\left(N_{t}-H_{t}\right)+\epsilon_{t} \\
\epsilon_{t} & \sim \operatorname{Normal}\left(0, \sigma^{2}\right) .
\end{aligned}
$$

Within the simulation, the model is fit at each time step with the available data $\left(H_{t}\right.$ and $N_{1: t}$, where $t$ is the current year within the simulation) to estimate the unknown parameters, $\beta_{0}, \rho$, and $\epsilon$ and project the population a single time step. This was done using the $\mathrm{R}$ package 'FitAR' (McLeod and Zhang 2008). We considered harvest to be additive to natural mortality.

\section{Model 2}

Model 2 is a discrete logistic growth model, defined as,

$$
N_{t+1}=N_{t}+r \times N_{t}\left(1-\frac{N_{t}}{K_{t}}\right)-H_{t}
$$

This model assumes $K_{t}$ is fixed at 30,000, recognizing that estimating carrying capacity is often infeasible. The intrinsic growth rate $(r)$ is defined based on juvenile recruitment $\left(P_{t}\right)$ and differential survival of juveniles and adults (Appendix S2). Survival parameters are stochastic and defined via probability distributions, while $P_{t}$ is data that is observed annually. As such, in every time step, $r$ changes based on the realized survival probabilities and the observed juvenile recruitment. We considered harvest to be additive to natural mortality. 


\section{Models 3 and 4}

Model 3 is a density-independent five age stochastic population model, where harvest mortality is additive. The fifth age represents all individuals that are five or older. Model 4 is the same population model but harvest is compensated for all ages up to natural mortality. Survival is stochastic with means for ages 1,2 , and $3-5$ as $0.85,0.94$, and 0.96 , respectively. Thus, survival rates are similar to the Generating Model near the carrying capacity, but not equivalent; fecundity of individuals $\geq 5$ years old is equivalent to the fecundity of individuals $\geq 8$ years old of the Generating Model. In both models, only individuals $\geq 5$ breed and only a proportion of them annually produce young (Appendix S2).

\section{Model 5}

Model 5 is the Generating Model, except harvest is assumed to be additive to mortality, rather than compensated up to natural mortality.

\section{Model 6}

Model 6 is a moving three-year average (MTYA) estimator, $N_{t+1}=\frac{N_{t-2}+N_{t-1}+N_{t}}{3}-H_{t}$, where $t$ is the most current year. Stochasticity is incorporated by assuming each count is observed from a Normal distribution with the count as the mean and an assumed standard deviation of 0.07, which was estimated from the RMP monitoring data (Gerber and Kendall 2017). This estimator is often used to smooth counts in population monitoring of migratory birds and threatened populations (Gerber and Kendall 2017). We considered harvest to be additive to natural mortality.

\section{Scenarios}

We consider nine simulation scenarios that vary in their combinations of elements (i.e., structural, monitoring, and decision framework; Table 1). For each scenario, a population trajectory from the Generating Model is simulated 1000 times with an initial 20 year period 
without harvest, followed by an 80-year period with harvest ( $t=21$ to 100; Box 1). Population trajectories are initialized with 20,000 cranes with an age-structure biased towards

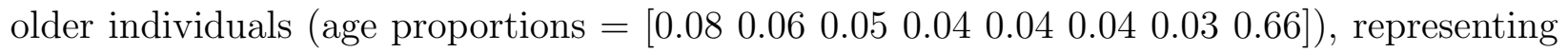
the general conditions of the RMP (Gerber 2015). We consider a set of scenarios with differing combinations of types of uncertainty so that we can explore how singular and multiple uncertainties affect meeting our population objective and harvest decisions (Table 1).

Scenarios 1-6 provide a balanced set to evaluate how different sources of uncertainty (singularly and multiple) affect meeting the population objective when monitoring the total population size with and without error, choosing an ARM or reactive decision framework, and considering structural uncertainty with and without the true model (i.e., Generating Model). Scenarios 1-4 use ARM for making harvest decisions, but vary by whether the model set includes the Generating Model and a close variant (Model 5) and whether the population is observed with or without error; these scenarios involve only observing total population size (similar to the current RMP monitoring) and require assumptions about the age-structure. Similar to the current situation with the RMP, we assume the age-structure was estimated once and represents the best available data. Thus, age-structured population models use this age-structure and the observed population size within the simulation to make predictions. Scenarios 5 and 6 use the reactive decision framework, such that there is no model set or assumptions of age-structure, but vary by whether the population is observed with error or not.

We also include a posthoc scenario (7), which mimics scenario 4, except that the model set does not include Model 1; preliminary results indicated the dominance of this model, and thus we were interested in understanding whether removing it from the model set would lead to drastically different model averaged population predictions and thus a different probability of meeting the objective. Lastly, we consider two baseline scenarios, where the population size and structure are monitored without error and the model set includes the Generating Model (scenario 8) and when the only model considered is the Generating Model 
(scenario 9). Scenario 8 allows us to understand the benefits of eliminating all uncertainties

(not including the variability caused by stochasticity), except which model is best (i.e., structural uncertainty), and to characterize the rate of learning that is possible when an ideal monitoring process is in place and the true model is hypothesized. Scenario 9 captures the best case, where there is no uncertainty in the monitoring process, the decision framework, or which model is most appropriate; this provides a baseline of what is possible when optimal decisions are made at the total population level for an age-structured population, rather than age-specific optimal decisions (Hauser et al. 2006). Hauser et al. (2006) make a compelling argument that managing a population with significant stage/age-structure is complicated by transient non-linear dynamics (Gerber and Kendall 2016), such that meeting population objectives might require making age-specific optimal decisions, rather than optimal decisions at the total population, which can't control for transient dynamics. While Scenario 9 takes into account the true age-structure, optimal decisions are made at the total population level and not individual ages, thus transient dynamics and especially population momentum could lead to trajectories above or below the population objective. We see this as an important distinction as it recognizes that age-specific harvesting of sandhill cranes and many other hunted species is not realistically achievable.

We compare scenarios by investigating the expected (i.e., averaged) probability of meeting the population objective (average proportion of years where the true population lies between 17,000-21,000) over the 80 years harvest decisions are made. Additionally, we characterize the best and worst possible outcomes of a scenario by calculating the maximum and minimum annual probability of meeting the population objective. Although not an explicit objective, we also report differences in expected annual harvest over the years.

\section{The value of eliminating uncertainties}

We use a value of information approach to consider eliminating all or partial uncertainty in regards to making harvest decisions (see, Yokota and Thompson 2004, Johnson et al. 2014). 
Specifically, we compare results across scenarios to understand the value of eliminating the different types of uncertainties associated with making decisions (i.e., monitoring, structural, decision framework), in terms of meeting the management objective. We do so by quantifying the difference in the expected probability of meeting the management objective between scenarios 1-8 versus scenario 9, where there are no uncertainties (All Uncertainties). Thus, we are specifically quantifying the expected change in meeting the population objective when all uncertainties have been eliminated $\left(\Delta_{A l l}\right)$. If the change in the expected probability of meeting the population objective is zero, there is no value in eliminating the uncertainties, in terms of meeting the population objective. To understand the value of eliminating one or more uncertainties, but not all uncertainties (Partial Uncertainties), we compare scenarios 1 through 8 with each other, which include different combinations of types of uncertainties. Thus, we calculate the difference in expected probability of meeting the management objectives between these scenarios $\left(\Delta_{\text {Partial }}\right)$. Higher values indicate a greater value of eliminating uncertainties, in regard to meeting the management objective. Note that we are calculating the expected difference of meeting the management objective across all three epochs (stable, increasing, and declining population) to obtain an overall assessment of the different scenarios under these three important periods of population change.

For the purposes of these calculations, we consider the choice of decision framework as a source of uncertainty. In addition, we also investigate how reducing uncertainty affects annual harvest, which is an important outcome, but not an explicit management objective; it does not influence the value of information, but is useful to understand population trajectories.

\section{Results}

\section{ARM decision framework}

We found ARM scenarios (scenarios 1-4, 7-9) varied substantially in their expected annual probability of maintaining the RMP objective, by whether the population was observed with 
error (scenarios 1, 4, 7) or was observed without error (scenarios 2-3, 8, 9; Table 1, Figs. 2, 3). The expected probability of maintaining the population objective over the duration of harvest when the population was observed with error ranged from 0.74 to 0.88 , while the minimum values ranged from 0.43 to 1.00 (Table 1). The expected annual probability of meeting the objective was lowest under the posthoc scenario (7), while the lowest minimum probability of meeting the objective was with scenario 1 . Scenarios where the population was observed with error led to differences in the extent of populations going below or above the objective, depending on the model set.

In all scenarios where the population was monitored without error (scenarios 2-3, 8, 9 ), we found the minimum annual probability of maintaining the population objective was 0.98 (Table 1). Of the scenarios that did not include the Generating Model for predictions, these consistently met the population objectives (see Learning). The overall expected annual harvest varied among scenarios (range, 635-818; Table 1). When there was no monitoring or structural uncertainty (scenario 9), such that the only model considered was the Generating Model (Fig. 2), the probability of meeting the objective was always 1.00. Despite not having age-specific optimal harvest decisions under scenario 9, the annual predictions were highly accurate (Fig. 3); the expected annual harvest was found to vary from 391 to 1363, corresponding to the changes in carrying capacity and thus the effects of density-dependence on vital rates.

\section{Learning}

We found that when the population was observed with error, Model 1 (autoregressive timeseries model) accumulated weight quickly and completely (scenarios 1 and 4; Fig. 4). This led to adequate performance overall in meeting the population objective (Table 1). However, it performed worst when the carrying capacity increased, such that Model 1 did not respond quickly, allowing the population to move beyond the upper population objective because harvest was not adequately increased during this time period (Fig. 3). By removing 
Model 1 in our posthoc scenario (7), we found that Model 2 (logistic growth model) slowly accumulated most of the weight and performed similarly to Model 1. Model 1 appeared to dominate Model 2 because of its larger prediction variance.

When the population was observed without error, the model set and whether agestructure was assumed or known had an important impact on which models accrued weight. But, the differences did not affect the probability of meeting the objective, which was almost always 1.00. When we assumed the age-structure and neither the Generating Model nor its variant (Model 5) were in the set (scenario 3), Model 3 (5-age population model) mostly dominated (Fig. 4). When the population size was observed without error and the model set included the Generating Model and Model 5, the Generating Model quickly accumulated almost all model weight. However, while this was maintained throughout when the population structure was known annually (scenario 8), its weight quickly declined as the carrying capacity did when the population structure was assumed (scenario 2).

\section{Reactive decision framework}

We found that making harvest decisions based on the reactive framework (scenarios 5 and 6) led to the lowest expected probability of meeting the management objective, which was still relatively high at 0.72 and 0.77 , respectively; these scenarios led to the highest overall expected annual harvest. Scenarios 5 and 6 also led to the lowest minimum annual probability of meeting the population objective $(<0.01)$. The expected probability of meeting the population objective was slightly better when the population was observed perfectly (Table 1). When the carrying capacity was either stable or decreasing, the reactive decision framework set harvest levels that caused the population to settle near the lower boundary of the population objective (Fig. 5). We found that when the population was observed with error (scenario 6), this led to observed counts that were below the allowable harvest level $(15,000)$ and thus harvest was closed in rare circumstances (Fig. 5). In years when the carrying capacity was increasing, the reactive decision framework appropriately allocated harvest 
to maintain the population within the bounds of the objective, regardless of whether the population was observed with error.

\section{The value of eliminating uncertainties}

The largest $\Delta_{A l l}(0.28)$ occurred when resolving all uncertainties associated with managing under the RMP decision framework while observing the population with error (difference between scenario 5 and 9; Table 2). This includes adopting an optimal decision process where the population size and structure is observed perfectly and there is no structural uncertainty. This would guarantee meeting the objective, although with an expected loss of annual harvest of 171 cranes. Within the ARM scenarios, we found the largest improvement (i.e., $\Delta_{\text {All }}$ of 0.26) when resolving all uncertainties in the posthoc scenario (7), which did not include Model 1, the Generating Model, or it's variant, Model 5. There is almost no improvement in meeting the population objective when the only uncertainties that require resolution are age-structure and structural uncertainty (i.e., choosing the best model). The expected benefit of resolving monitoring uncertainties was higher in an ARM framework $\left(\Delta_{\text {Partial }}=0.14-0.15\right)$ than if an ARM framework is not adopted $\left(\Delta_{\text {Partial }}=0.05\right.$, Table 2$)$.

Changing from the reactive to an ARM decision process always increased the probability of meeting the population objective, regardless of resolving any additional uncertainties (Table 2; rows where resolved uncertainty contain 'DF'). However, there was little value gained when changing to an ARM process if the population was observed with error and the model set didn't include Model $1\left(\Delta_{\text {Partial }}=0.02\right)$. In all cases of changing from the RMP decision process to an ARM process, there is a decrease in annual expected harvest (Table 2).

\section{Discussion}

Our findings strongly support the utility of the ARM framework to achieve population objectives, even when model sets only include models that are known to be deficient repre- 
sentations of true population processes. We found the single most important uncertainty to resolve was the appropriate decision process (Moore and Conroy 2006). The second most important was monitoring uncertainty, such that the true population state was known. If population monitoring data are highly variable due to sampling variation that can not be controlled and/or empirical knowledge is limited for constructing realistic population models, ARM model sets should include a range of model types, including simple mechanistic, descriptive, and purely predictive models.

An important, but surprising finding was that optimal age-specific harvest decisions were unnecessary to meet the population objective (Hauser et al. 2006; see Johnson et al. 2018 for similar findings). Rather, optimal harvest decisions without regard to age-structure permitted meeting the objective. In fact, even when using simple population models, when the current age-structure was assumed, our optimal population-level harvest decisions led to meeting the objective when the population was observed without error. The reason for this was likely that the stochastic age-structure did not vary substantially and that transient dynamics were not extreme (see Gerber and Kendall 2016); as the discrepancy between the assumed and realized population age-structure increases, the probability of meeting a population objective will decrease (B. Gerber, unpublished data). This is an especially important finding, given that many migratory birds, including sandhill cranes, cannot be aged beyond a short immature period, so age-specific harvest allocations are not practical.

\section{Learning within Adaptive Management}

Learning is an important component of ARM, insofar as it improves predictions for future management decisions (Williams 2011a). In most ARM programs, the model set is composed of a small set of hypothesized process-driven models (Johnson et al. 1997). Therefore, learning within the ARM process is specifically focused on better understanding the fundamental components of the ecological process, which should ideally provide more robust predictions of the system, even when observations range outside of past conditions. We 
highlight an alternative approach in selecting a model set; we included population models that were motivated by underlying dynamics of sandhill cranes (e.g., Models 2-4), as well as purely functional models, such as the autoregressive time-series model (Model 1) and the moving three year estimator (Model 6).

Our model sets recognize that in some or all years, empirically parameterized crane population models may poorly represent the true dynamics, either because of monitoring uncertainties or because the dynamics that are governing population change are poorly captured (e.g., Model 3 is density-independent, while the Generating Model is density-dependent). As such, our 'learning' is aimed at identifying the most useful predictive model(s) in the set for a given set of circumstances. Our goal for learning is to provide the best predictions to make harvest decisions that will meet our management objectives, not necessarily to perfectly characterize the system. Ideally, we would most benefit if we could identify a model that captures the fundamental aspects of the true system processes, but we acknowledge that this is not always feasible. A potential risk of this approach is that all models may do poorly when faced with highly different observations than what is typical. Here, process-driven models are especially useful.

Perhaps though, the expectations of identifying ecological hypotheses with correct dynamics should be tempered, based on the ease with which model weight can accrue with incorrect models, even in the presence of the correct model (this study; Conn \& Kendall 2004); this can happen when models have different variance structures (e.g., some models' predictions are highly precise compared to others) or when the observational process isn't corrected for and masks the true population trajectory. It is satisfying that the ARM learning process correctly identified the Generating Model with $100 \%$ weight, but only when the population size and age-structure was annually observed without error. Thus, if monitoring data were accurate and we hypothesized the true population process, we could quickly identify it as the best ecological model through model weight updating ( $\geq 0.9$ model weight in less than ten years). However, more commonly than not, this is unlikely to be the case 
and it should be recognized that a set of poorly realistic models and imprecise monitoring can cause misleading ecological learning about the system. For example, in our scenario 1, the model set included the Generating model, but no weight was given to it because we observed the population with error and did not know the true age-structure. Furthermore, even when we did observe the population perfectly, the Generating Model was well supported for only part of the simulation, likely due to the assumption of age-structure. However, a set of poorly realistic models and imprecise monitoring may not jeopardize ARM's ability to improve management decisions and perform better than a reactive approach, as long as the model set in total provides robust predictions.

The quality and rate of learning in ARM will likely depend on whether model parameters are updated along with the model weights on an annual basis, at longer time periods, or not at all. Our models varied in whether parameters were annually updated based on new data (Models 1-2) or not (Models 3-6). Being able to update model parameters is likely a more efficient way to learning, improving predictions, and thus improving management decisions. However, whether parameters can be updated depends on whether monitoring or additional research is being done jointly to estimate demographic parameters, such as survival. This will likely be unique to different programs. For RMP sandhill cranes, survival is not monitored annually and thus updating it is not feasible. Additional research should identify the value of information of model parameter updating at multiple time scales.

Lastly, learning within ARM depends on how we measure the discrepancy between model predictions and observed state variables. Updating model weights using Bayes theorem is a logical and powerful approach. However, there are important consequences that should be noted. If a model poorly predicts in a given year, the $P\left(N_{t+1} \mid M_{o d e l} l_{i, t}\right)$ can be approximated (e.g., rounding or discretization of an empirical distribution) at zero, such that the updated weight for model $i$ will be zero, ensuring its effective removal from the model set. This is simply an outcome of using Bayes theorem. If all models poorly predict the new observation with a probability of zero, no model updating can be performed. Similarly, 
we found it common that models with the largest prediction variances accumulated most of the weight. The $P\left(N_{t+1} \mid\right.$ Model $\left._{i}\right)$ accounts for both the bias and precision of a model's prediction, which may lead to giving models that are highly imprecise and somewhat biased more weight, compared to other models that are based on more reasonable hypotheses, but are overly precise (Appendix S1: Fig. S3).

\section{Sandhill crane management}

For sandhill crane management, there is a higher risk of not meeting the RMP population objective by managing under the current reactive framework, compared to an ARM framework. By explicitly recognizing the uncertainty about how the population will change from one year to the next, there is an inherent conservatism in harvest decisions compared to a reactive decision process. The primary deficiency in the RMP harvest framework occurs when the carrying capacity is stable or declining. In either case, harvest is allocated to a degree that causes the population to be pushed to and sometimes below the lower bound of the population objective $(17,000)$, regardless of whether the population is monitored without error. This occurs even with compensation up to natural mortality. We can expect the population to decline more sharply and to a greater extent outside of the population objective if harvest mortality is less compensatory or is strictly additive to natural mortality.

We found that the reactive decision framework performed well when the carrying capacity increased, thus dampening negative density-dependent processes, which caused increases in survival and juvenile productivity and led to population increases beyond the population objective when unharvested. When the total population size was observed with or without error, this decision framework kept the population from exceeding the upper population objective. This was not the case for ARM scenarios when the population was observed with error; monitoring uncertainty led to the population models not predicting the increasing population quick enough in order to increase harvest at the appropriate rate. However, the simulated RMP decision process relied on accurate knowledge of juvenile re- 
cruitment $\left(P_{t}\right)$. If $P_{t}$ was biased low, it would decrease harvest and thus allow the population to exceed the upper population objective, depending on the level of bias, while the reverse is true if $P_{t}$ was biased high (B. Gerber, unpublished data).

As with many animal populations involving anthropogenic take, management decisions related to allowable take or how the type of regulations (e.g., daily bag limit, season length) translates into the number of individuals taken is not exact nor even straightforward (Nichols et al. 1995). Managers usually only have partial control over harvest decisions (Williams 2011a). While we did not explicitly investigate the uncertainty regarding partial controllability, there are some important considerations for sandhill crane decision making. Most important is that the RMP annual harvest is routinely lower than the total allowable annual harvest (although this proportion is increasing) and that allocation fulfillment varies across breeding and wintering states; Appendix S2: Fig S1). We can expect harvest decisions would likely have a lesser impact on the population than indicated in our results and perhaps increase the probability of meeting the population objective in years the population is stable without harvest. Conversely, this may also lead to increased probability that the population exceeds the objective in some years. Accounting for partial controllability could be done simply, given that the allocation harvest and estimated harvest by state are known (Appendix S2); if the Generating model was affected only through partial fulfillment of the harvest allocation and the models also adjusted for it, we expect our results to be similar, except that allocated hunting permits would exceed harvest.

\section{Conclusion}

Ultimately, the decision to adopt an ARM framework will depend on whether managers decide the benefits of the ARM process outweigh the cost of its increased complexity, compared to the simplicity, but increased risks of the current reactive process. We found the current RMP crane decision process performed adequately overall. A major limitation of non-model based decision frameworks, is the difficulty of accommodating future necessary 
changes in a logical way (e.g., changes in the timing of management decisions, partial controllability). By using a coherent and logical approach to population prediction and decision making, such as ARM, there is a foundational basis to implement future changes as needed (e.g., altered system models to accommodate climate change). However, as of yet, despite the lack of motivating theory and reactive nature of the RMP crane decision process, the RMP objective has been met in every year since 1997, except for one. The lack of a current problem is a strong motivation for decision makers to maintain the status quo, avoiding the short-term costs of modifying the decision process. Crane managers would need to consider the potential consequences of the two decision processes and decide whether the trade-offs in logical complexity and increased expected performance in meeting objectives outweighs limited functional simplicity that has been shown to perform adequately, so far.

\section{Acknowledgments}

Funding was provided by the U.S. Fish and Wildlife Service's Webless Migratory Game Bird Program and their Mountain-Prairie Migratory Bird Office. We are grateful to edits provided by M. Hooten, Y. Wei, P. Doherty, and two anonymous reviewers. Any use of trade, firm, or product names is for descriptive purposes only and does not imply endorsement by the U.S. Government.

\section{References}

Case, D., and S. Sanders. 2009. Priority information needs for sandhill cranes: a funding strategy. Technical Report, U.S. Fish and Wildlife Service.

Chadès, I., Chapron, G., Cros, M. J., Garcia, F., \& Sabbadin, R. 2014. MDPtoolbox: a multi-platform toolbox to solve stochastic dynamic programming problems. Ecography, 37:916-920.

Chamberlin, T. C. 1890. The method of multiple working hypotheses. Science, 15:92-96. 
Conn, P. B., \& Kendall, W. L. 2004. Evaluating mallard adaptive management models with time series. Journal of Wildlife Management, 68:1065-1081.

Drewien, R. C., W. M. Brown, and W. L. Kendall. 1995. Recruitment in Rocky Mountain Greater Sandhill Cranes and comparison with other populations. Journal of Wildlife Management, 59:339-356.

Drewien, R. C.; Brown, W. M.; Lockman, D. C.; Kendall, W. L.; Clegg, K. R.; Graham, V. K. \& Manes., S. S. 2001. Band recoveries, mortality factors, and survival of Rocky Mountain greater sandhill cranes. Hornocker Wildlife Institute, Bozeman, MT.

Drewien, R.C. 2011. Recruitment survey of the rocky mountain population of greater sandhill cranes. Unpublished Report, U.S. Fish and Wildlife Service, Migratory Bird Office.

Eberhardt, L. L. 2002. A paradigm for population analysis of long-lived vertebrates. Ecology, 83:2841-2854.

Gannon, J.J., Shaffer, T.L., Moore, C.T. 2013, Native Prairie Adaptive Management: A Multi Region Adaptive Approach to Invasive Plant Management on Fish and Wildlife Service Owned Native Prairies: U.S. Geological Survey Open File Report 20131279, 184 p. http://dx.doi.org/10.3133/ofr20131279.

Gerber, B.D., Dwyer, J.F., Nesbitt, S.A., Drewien, R.C., Littlefield, C.D., Tacha, T.C. et al. 2014. Sandhill crane (Grus canadensis), The Birds of North America Online (ed. A. Poole), Cornell Lab of Ornithology, Ithaca. http://bna.birds.cornell.edu/bna/species/031.

Gerber, B. 2015. Sandhill crane population monitoring, modeling, and harvest decision making. PhD Dissertation, Colorado State University, Fort Collins, USA.

Gerber, B. D., Kendall, W. L., Hooten, M. B., Dubovsky, J. A., \& Drewien, R. C. 2015. Optimal population prediction of sandhill crane recruitment based on climate-mediated habitat limitations. Journal of Animal Ecology, 84:1299-1310. 
Gerber, B. D., \& Kendall, W. L. 2016. Considering transient population dynamics in the conservation of slow life-history species: An application to the Sandhill Crane. Biological Conservation, 200:228-239.

Gerber, B. D. and Kendall, W. L. 2017. Evaluating and improving count-based population inference: a case study of monitoring sandhill cranes over thirty-one years. Condor: Ornithological Applications, 119:191-206.

Gerber, B. D., Converse, S. J., Muths, E., Crockett, H. J., Mosher, B. A., \& Bailey, L. L. (2017). Identifying Species Conservation Strategies to Reduce DiseaseAssociated Declines. Conservation Letters. https://doi.org/10.1111/conl.12393

Gregory R., Failing L., Harstone M., Long G., McDaniels T., Ohlson D. 2012. Structured decision making: a practical guide to environmental management choices. John Wiley \& Sons.

Hall, J. A., \& Fleishman, E. 2010. Demonstration as a means to translate conservation science into practice. Conservation Biology, 24:120-127.

Hauser, C. E., Cooch, E. G., \& Lebreton, J. D. 2006. Control of structured populations by harvest. Ecological Modelling, 196:462-470.

Holling, Crawford S. Adaptive environmental assessment and management. 1978. London, Wiley.

Johnson, F. A., Moore, C. T., Kendall, W. L., Dubovsky, J. A., Caithamer, D. F., Kelley Jr, J. R., \& Williams, B. K. 1997. Uncertainty and the management of mallard harvests. Journal of Wildlife Management, 61:202-216.

Johnson, F. A., Jensen, G. H., Madsen, J., \& Williams, B. K. (2014). Uncertainty, robustness, and the value of information in managing an expanding Arctic goose population. Ecological Modelling, 273:186-199. 
Johnson, F. A., Alhainen, M., Fox, A. D., Madsen, J., \& Guillemain, M. (2018). Making do with less: must sparse data preclude informed harvest strategies for European waterbirds?. Ecological Applications. http://dx.doi.org/10.1002/eap.1659

Kendall, W.L. (2001). Using models to facilitate complex decisions. Modeling in natural resource management: development, interpretation and application (eds T.M. Shenk \& A.B. Franklin), pp 147-170. Island Press, Washington D.C., USA.

Kendall, W. L., and C. T. Moore. 2012. Maximizing the utility of monitoring to the adaptive management of natural resources. Design and analysis of long-term ecological monitoring studies (eds, R.A Gitzen, A.B. Cooper, J.J. Millspaugh, \& D.S. Licht, pp.74-98. Cambridge University Press, Cambridge, UK.

Kruse, K.L. and J.A. Dubovsky. 2015. Status and harvests of sandhill cranes: mid-continent, rocky mountain and lower colorado river valley populations. Administrative Report, U.S. Fish and Wildlife Service, Lakewood, CO, USA.

Marescot, L., Chapron, G., Chadé, I., Fackler, P. L., Duchamp, C., Marboutin, E., \& Gimenez, O. 2013. Complex decisions made simple: a primer on stochastic dynamic programming. Methods in Ecology and Evolution, 4:872-884.

Martin, J., Runge, M. C., Nichols, J. D., Lubow, B. C., \& Kendall, W. L. 2009. Structured decision making as a conceptual framework to identify thresholds for conservation and management. Ecological Applications, 19:1079-1090.

McGowan, C. P., Smith, D. R., Nichols, J. D., Lyons, J. E., Sweka, J., Kalasz, K., et al. 2015. Implementation of a framework for multi-species, multi-objective adaptive management in Delaware Bay. Biological Conservation, 191:759-769.

McLeod, A. I., \& Zhang, Y. (2008). Improved subset autoregression: With R package. Journal of Statistical Software, 28:1-28. 
Moore, C. T., \& Conroy, M. J. (2006). Optimal regeneration planning for old-growth forest: addressing scientific uncertainty in endangered species recovery through adaptive management. Forest Science, 52:155-172.

Nichols, J. D., Johnson, F. A., \& Williams, B. K. 1995. Managing North American waterfowl in the face of uncertainty. Annual review of Ecology and Systematics, 26:177-199.

Nichols, J D. 2001. Using models in the conduct of science and management of natural resources. Modeling in natural resource management: development, interpretation and application (eds T.M. Shenk \& A.B. Franklin), pp 11-34. Island Press, Washington D.C., USA.

Nichols, J.D. and B.K. Williams. 2006. Monitoring for conservation. Trends in Ecology $E^{8}$ Evolution, 21:668-673.

Regan, H. M., Colyvan, M., \& Burgman, M. A. 2002. A taxonomy and treatment of uncertainty for ecology and conservation biology. Ecological Applications, 12: 618-628.

Pacific Flyway Council and Central Flyway Council. 2016. Pacific and central flyways management plan for the Rocky mountain population of greater sandhill cranes. Pacific Flyway Council and Central Flyway Council, care of the U.S. Fish and Wildlife Services Pacific Flyway Representative, Vancouver, Washington. 47pp..

Sutherland, W.J., Pullin, A.S., Dolman, P.M., Knight, T.M., 2004. The need for evidencebased conservation. Trends in Ecology \& Evolution, 19:305-308.

Tacha, T. C., D. E. Haley, and P. A. Vohs. 1989. Age of sexual maturity in Sandhill Cranes from mid-continental North America. Journal of Wildlife Management, 53: 43-46.

U.S. North American Bird Conservation Initiative, Monitoring Subcommittee. 2007. Opportunities for Improving Avian Monitoring. US North American Bird Conservation Initiative.

Walker, B. 1998. The art and science of wildlife management. Wildlife Research, 25:19. 
Walters, C.J. Adaptive management of renewable resources. New York: Macmillan.

Westgate, M. J., Likens, G. E., \& Lindenmayer, D. B. (2013). Adaptive management of biological systems: a review. Biological Conservation, 158:128-139.

Williams, B. K., R. C. Szaro, and C. D. Shapiro. 2007. Adaptive management: the U.S. Department of the Interior technical guide. U.S. Department of the Interior, Washington, D.C., USA.

Williams, B. K. 2011a. Adaptive management of natural resources-framework and issues. Journal of Environmental Management, 92:1346-1353.

Williams, B. K. 2011b. Passive and active adaptive management: approaches and an example. Journal of Environmental Management, 92:1371-1378.

Wilson, G., and M. Woodraw. 2009. Kuka Kanyini, Australian Indigenous Adaptive Management. Adaptive Environmental Management (eds C. Allan \& G.H Stankey), pp. 117-141. Springer, Netherlands.

Yokota, F., \& Thompson, K. M. 2004. Value of information analysis in environmental health risk management decisions: past, present, and future. Risk Analysis, 24:635-650. 


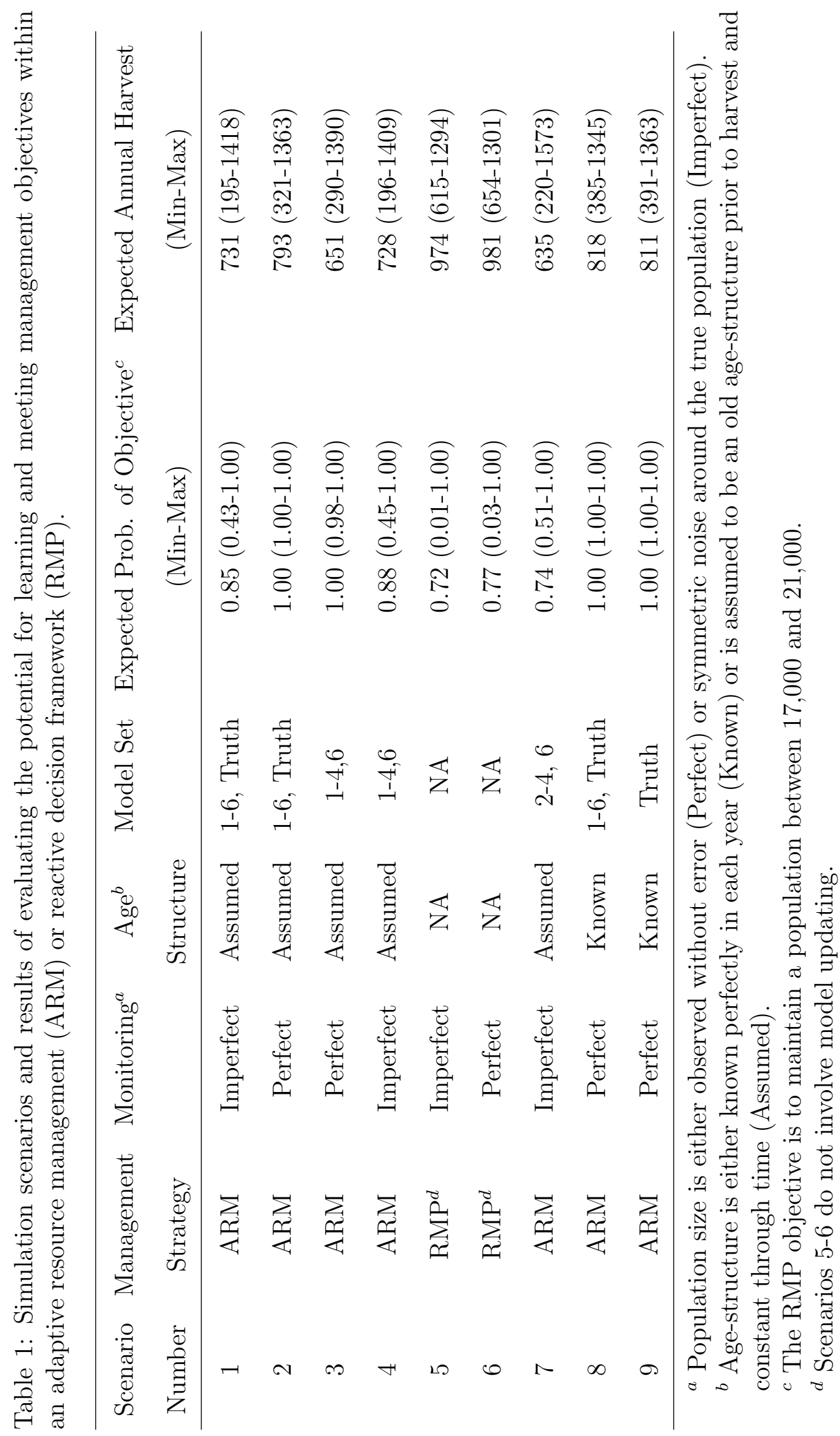


Table 2: Comparing scenarios to evaluate the improvement in meeting the population objective when all (All Uncertainties; $\Delta_{\text {All }}$ ) or partial (Partial Uncertainties; $\Delta_{\text {Partial }}$ ) uncertainties are resolved and the consequences to changes in expected harvest management decisions for the Rocky Mountain Population (RMP) of sandhill cranes.

\begin{tabular}{|c|c|c|c|c|c|}
\hline Scenario & Resolved $^{a}$ & Unresolved $^{a}$ & Model Set ${ }^{b}$ & Change in Prob & Change in Expected \\
\hline Comparison & Uncertainty & Uncertainty & & (Meeting Objective) & Harvest $^{c}$ \\
\hline \multirow[t]{7}{*}{ All Uncertainties $\left(\Delta_{A l l}\right)$} & Pop, SS, Models, DF & .. & .. & 0.28 & -170.45 \\
\hline & Pop, SS, Models & .. & $\mathrm{M} 2-4, \mathrm{M} 6$ & 0.26 & 175.36 \\
\hline & Pop, SS, Models & .. & M1-4, M6 & 0.14 & 82.77 \\
\hline & Pop, SS, Models & .. & M1-6, Truth & 0.15 & 79.46 \\
\hline & SS, Models & .. & M1-4, M6 & 0.00 & 160.17 \\
\hline & SS, Models & .. & $\mathrm{M} 2-4, \mathrm{M} 6$ & 0.00 & 18.17 \\
\hline & Models & .. & M1-6, Truth & 0.00 & -7.08 \\
\hline \multirow[t]{13}{*}{ Partial Uncertainties $\left(\Delta_{\text {Partial }}\right)$} & Pop & $\mathrm{DF}$ & .. & $0.05^{c}$ & 7.01 \\
\hline & Pop & SS, Models & M1-6, Truth & 0.15 & 61.29 \\
\hline & Pop & SS, Models & M1-4,6 & 0.14 & -77.39 \\
\hline & SS & Models & M1-6, Truth & 0.00 & 25.24 \\
\hline & $\mathrm{DF}$ & Pop, SS, Models & M1-4, M6 & 0.14 & -246.21 \\
\hline & $\mathrm{DF}$ & Pop, SS, Models & M1-6, Truth & 0.13 & -242.90 \\
\hline & DF & Pop, SS, Models & M2-4, M6 & 0.02 & -338.79 \\
\hline & $\mathrm{DF}$ & SS, Models & M1-4, M6 & 0.23 & -330.62 \\
\hline & DF & SS, Models & M1-6, Truth & 0.23 & -188.62 \\
\hline & $\mathrm{DF}$ & Models & M1-6, Truth & 0.23 & -163.37 \\
\hline & Pop, DF & SS, Models. & M1-4, M6 & 0.28 & -323.60 \\
\hline & Pop, DF & SS, Models. & M1-6, Truth & 0.28 & -181.60 \\
\hline & Pop, SS, DF & Models & M1-6, Truth & 0.28 & -156.36 \\
\hline
\end{tabular}

${ }^{a}$ Uncertainty includes monitoring population abundance (Pop), age-structure (SS), models (Models), and the decision framework (DF). A resolved DF indicates that an ARM framework is used, while unresolved indicates the RMP framework. If DF is not included in a row then the probability of meeting population objective is being considered between ARM scenarios.

$b$ The model set indicates the scenario with unresolved uncertainty (see Table 1).

${ }^{c}$ Harvest is not a specific objective and does not effect the value of information. It is a byproduct of the system and decisions made to meet the objective. 
Box 1. Simulation Workflow: For each of nine scenarios, we simulate sandhill crane population dynamics and make annual harvest decisions to evaluate the robustness of meeting our population objective. Scenarios vary in the decision framework, whether the population is observed with error, and for the adaptive management framework, the model set.

Figure 1. As part of the Generating Model, we define a) stochastic carrying capacity over time (one realization), b) proportion of breeders under different population sizes in relation to carrying capacity, c) fecundity per capita under different population sizes in relation to carrying capacity, and d) mean survival by age under different population sizes in relation to carrying capacity. The vertical line at 1 indicates when the population is at carrying capacity

Figure 2. The expected true (top) or observed (bottom) annual probability of meeting the Rocky Mountain Population sandhill crane objective for different scenarios using an adaptive management framework for making harvest decisions. The legend indicates the scenario number, decision process, monitoring type, knowledge of age-structure (SS), and whether the model set included the true model.

Figure 3. Population dynamics and expected population predictions from the weighted average of the model set for six adaptive resource management scenarios that vary in model set, whether the population is observed with error, and whether the age-structure is observed annually. The population, observed population, and predicted population are presented at their means and 95\% quantiles. The gray area indicates the RMP population objective. SS is age-structure. Scenario 9 indicates optimal decision making using the Generating Model, such that there is no structural uncertainty.

Figure 4. Model weights through time for six adaptive resource management scenarios that vary in the model set with whether the population is observed with error, and whether the 
925

age-structure is observed annually or assumed. M1-6 indicates Models 1-6, True M indicates the Generating Model, and SS indicates age-structure.

Figure 5. Annual probability of meeting the objective for the Rocky Mountain Population of sandhill cranes ( $1^{\text {st }}$ row), mean total harvest and $95 \%$ quantiles ( $2^{\text {nd }}$ row), and population dynamics when the population is observed with and without error (mean and $95 \%$ quantiles; $3^{\text {rd }}$ row, Harvest decisions are made using the RMP decision framework (Scenario 5 and 6). The gray area of the third row figures indicates the RMP population objective. 


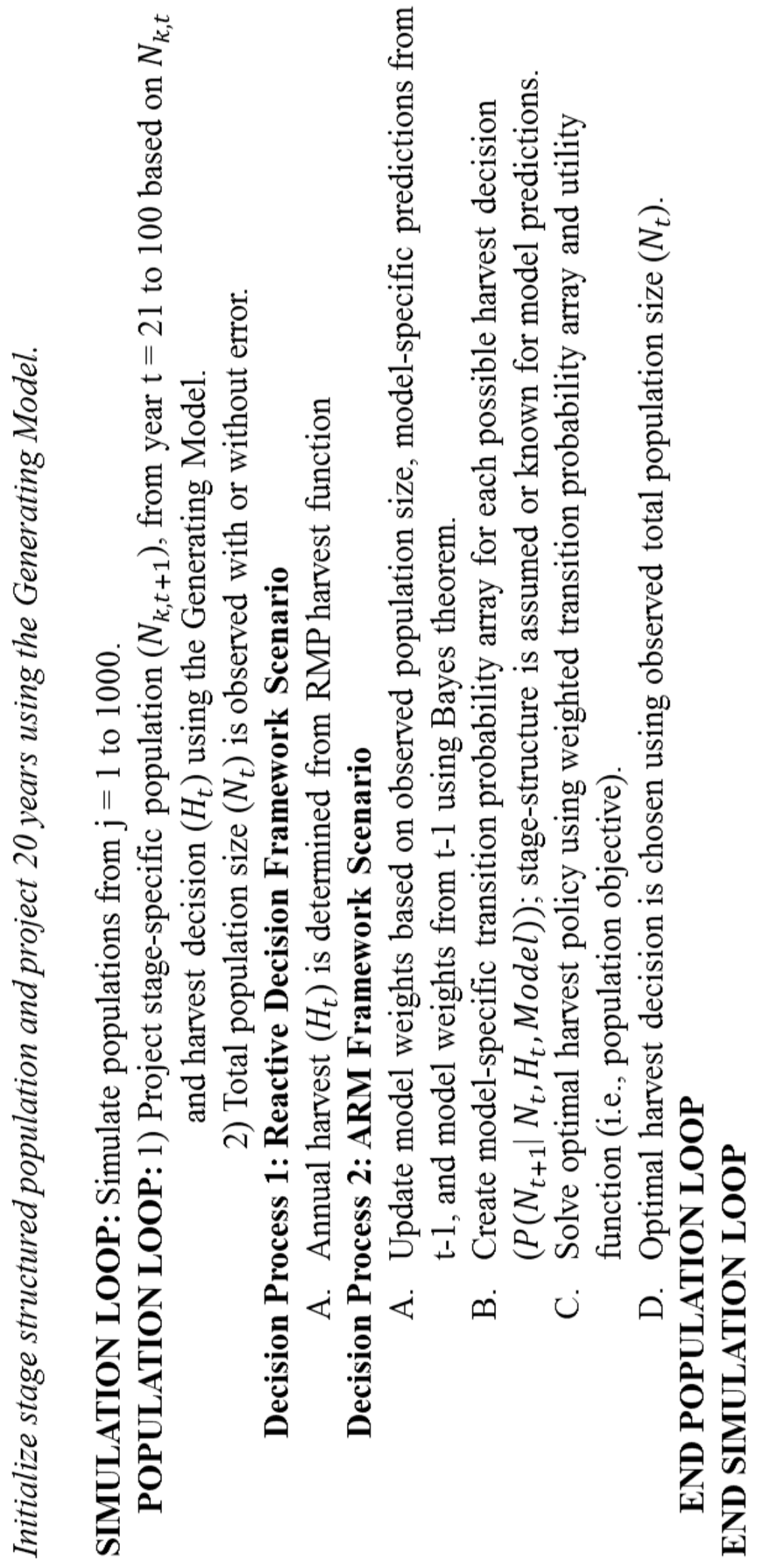




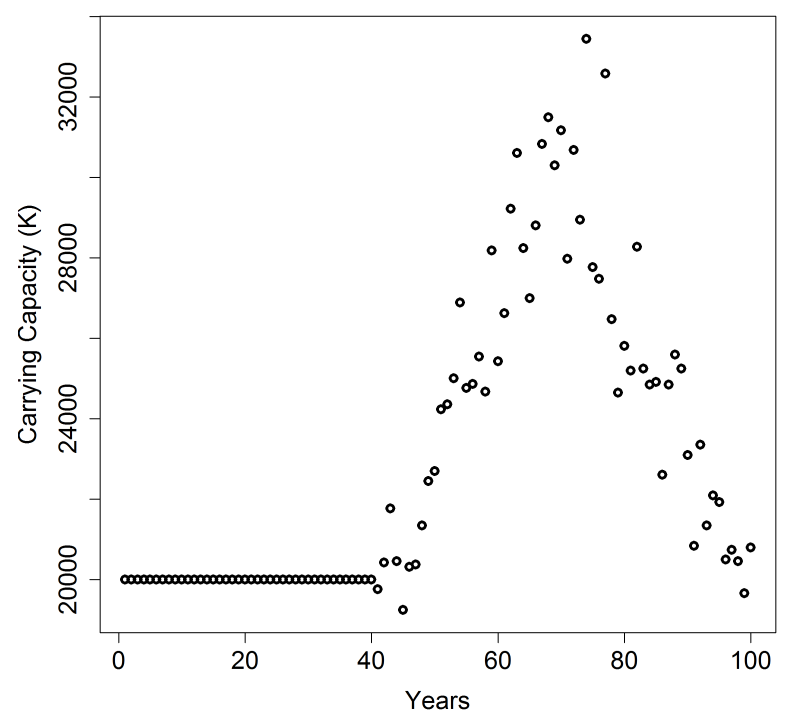

(a)

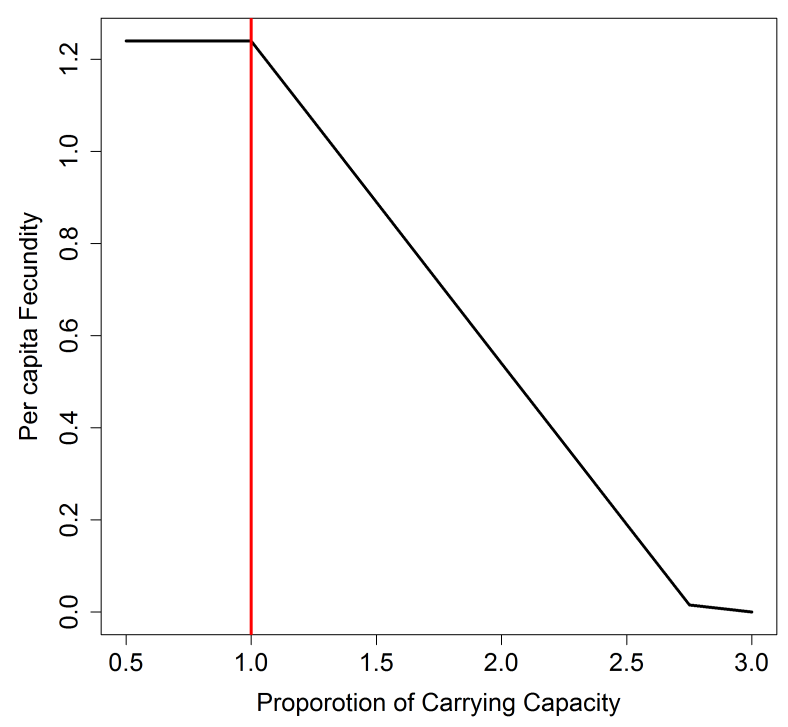

(c)

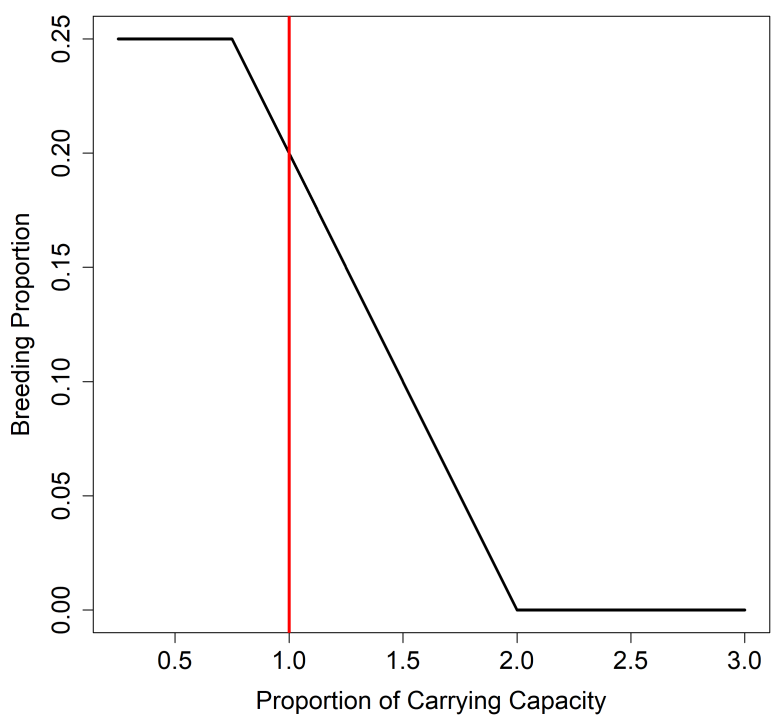

(b)

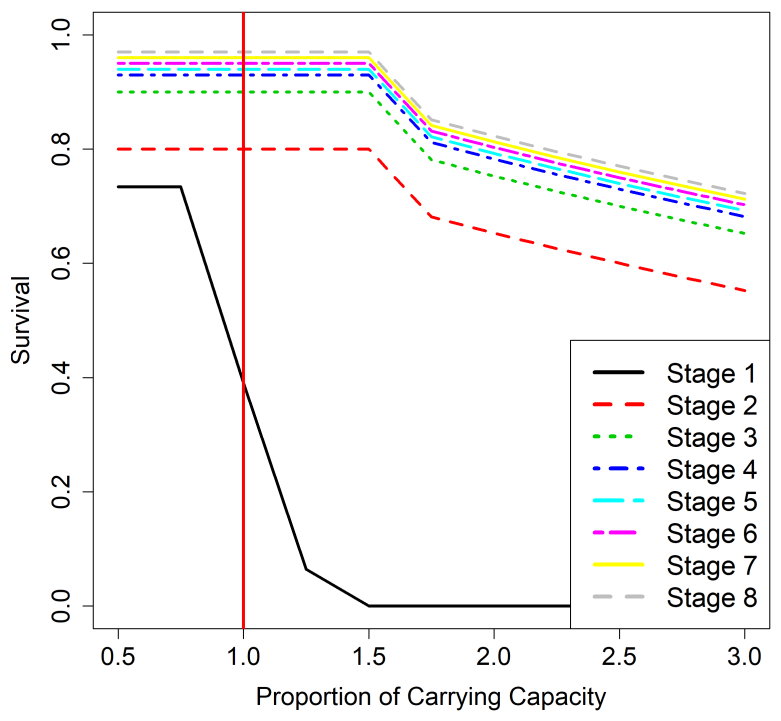

(d)

Figure 1 

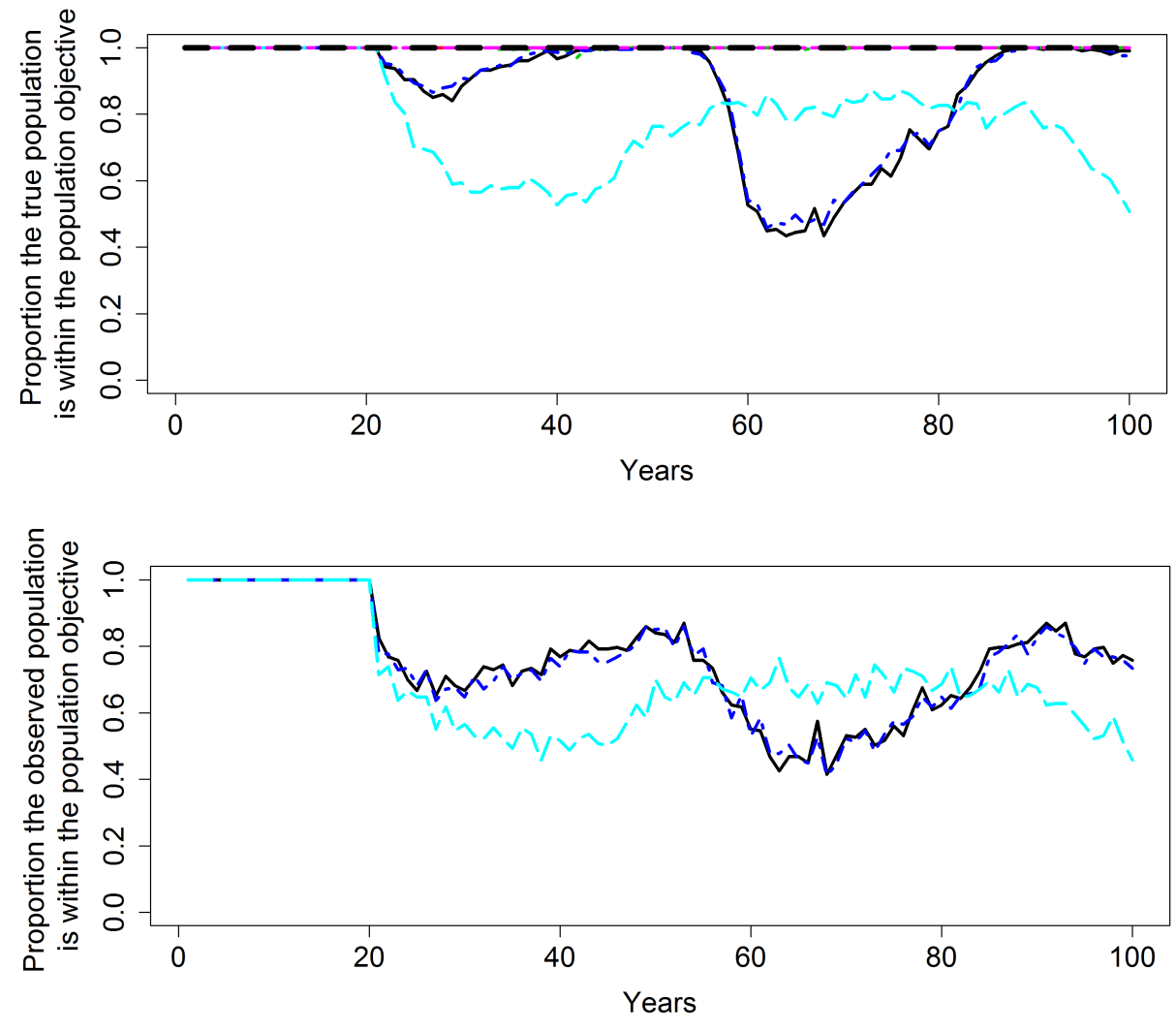

1, ARM, Imprecise Monitoring, Assumed SS, True Model in Set

- 2, ARM, Perfect Monitoring, Assumed SS, True Model in Set

- - 3, ARM, Perfect Monitoring, Assumed SS, Simple Models

- - 4, ARM, Imprecise Monitoring, Assumed SS, Simple Models

- 7, ARM, Imprecise Monitoring, Assumed SS, Simple Modes w/o Model1

- 8, ARM, Perfect Monitoring, Known SS, True Model in Set

- 9, ARM, Perfect Monitoring, Known SS, Only True Model

1, ARM, Imprecise Monitoring, Assumed SS, True Model in Set

- 4, ARM, Imprecise Monitoring, Assumed SS, Simle Models

- 7, ARM, Imprecise Monitoring Assumed SS, Simple Modes w/o Model1

Figure 2 


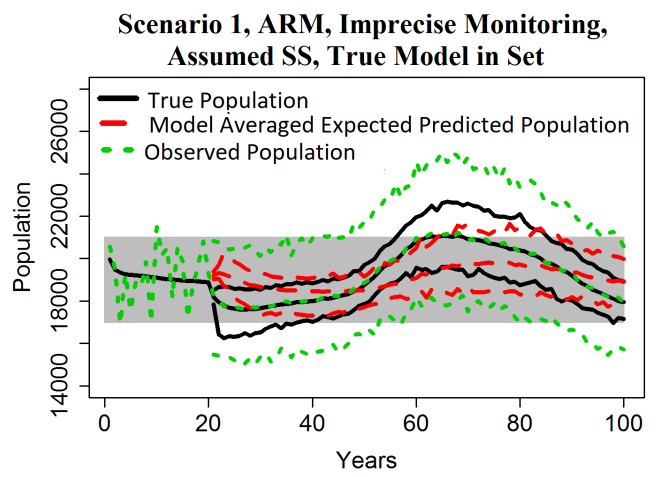

Scenario 3, ARM, Perfect Monitoring, Assumed SS, Simple Models

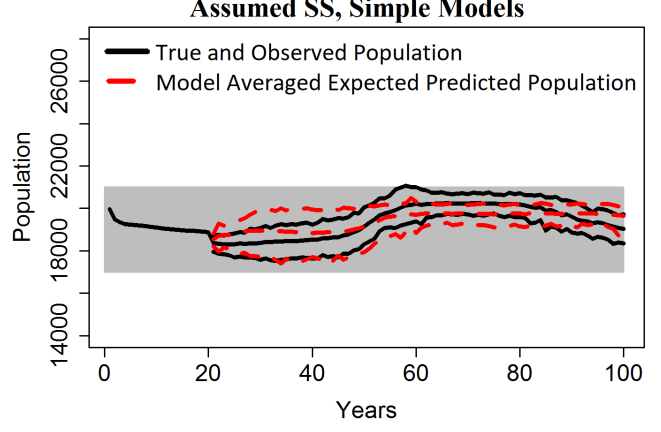

Scenario 7, ARM, Imprecise Monitoring, Assumed SS, Simple Models w/o Model1

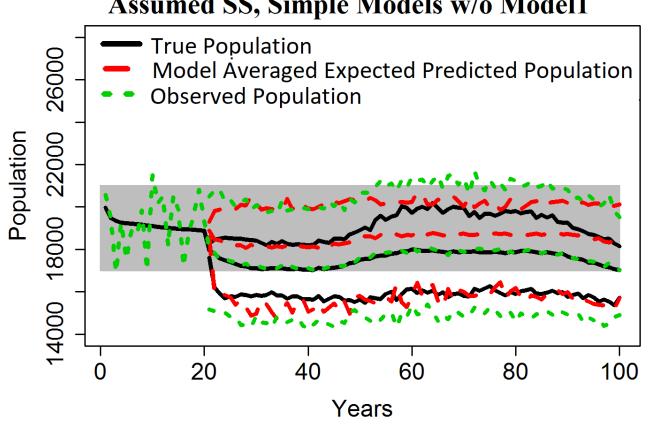

Scenario 2, ARM, Perfect Monitoring, Assumed SS, True Model in Set

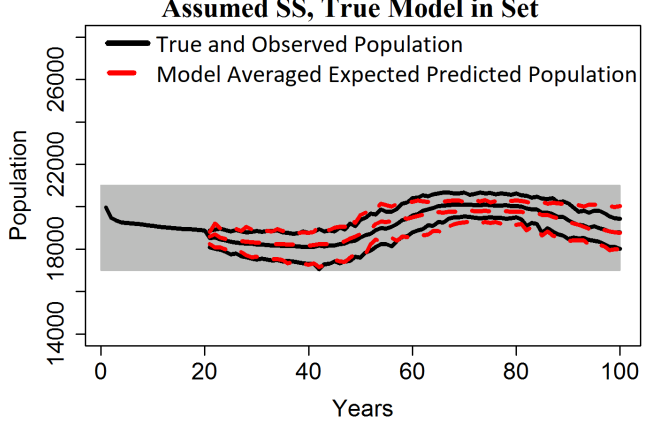

Scenario 4, ARM, Imprecise Monitoring, Assumed SS, Simple Models

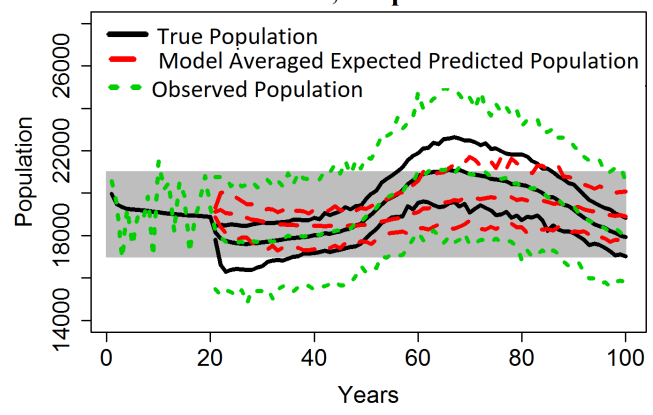

Scenario 8, ARM, Perfect Monitoring, Known SS, True Model in Set

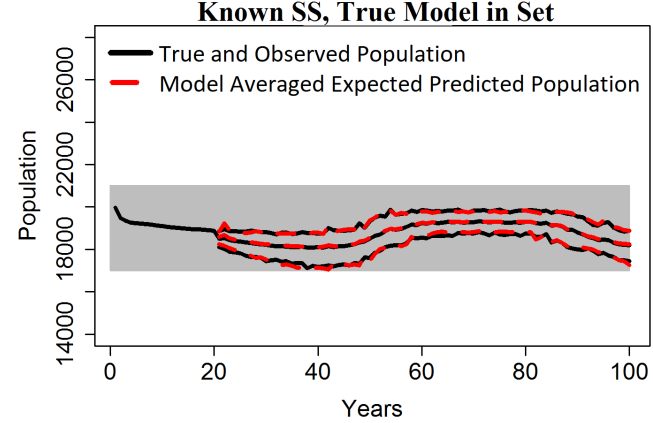

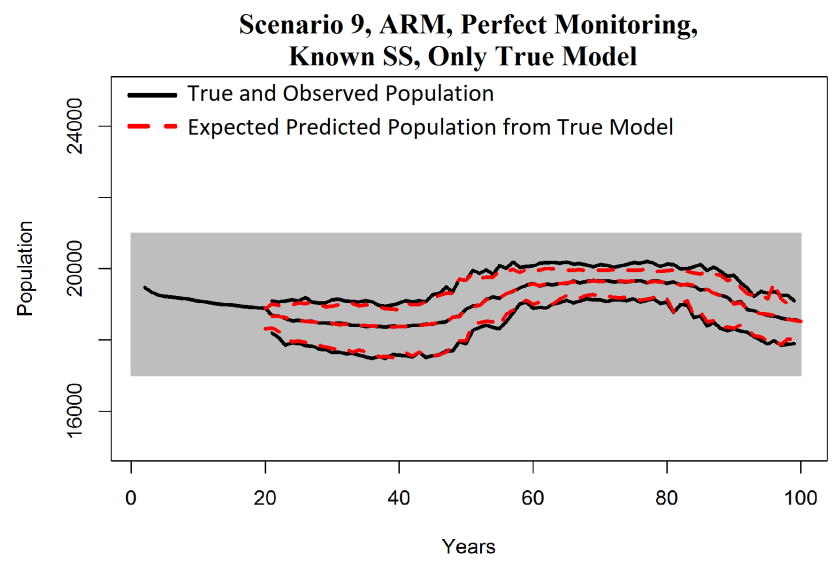

Figure 3 

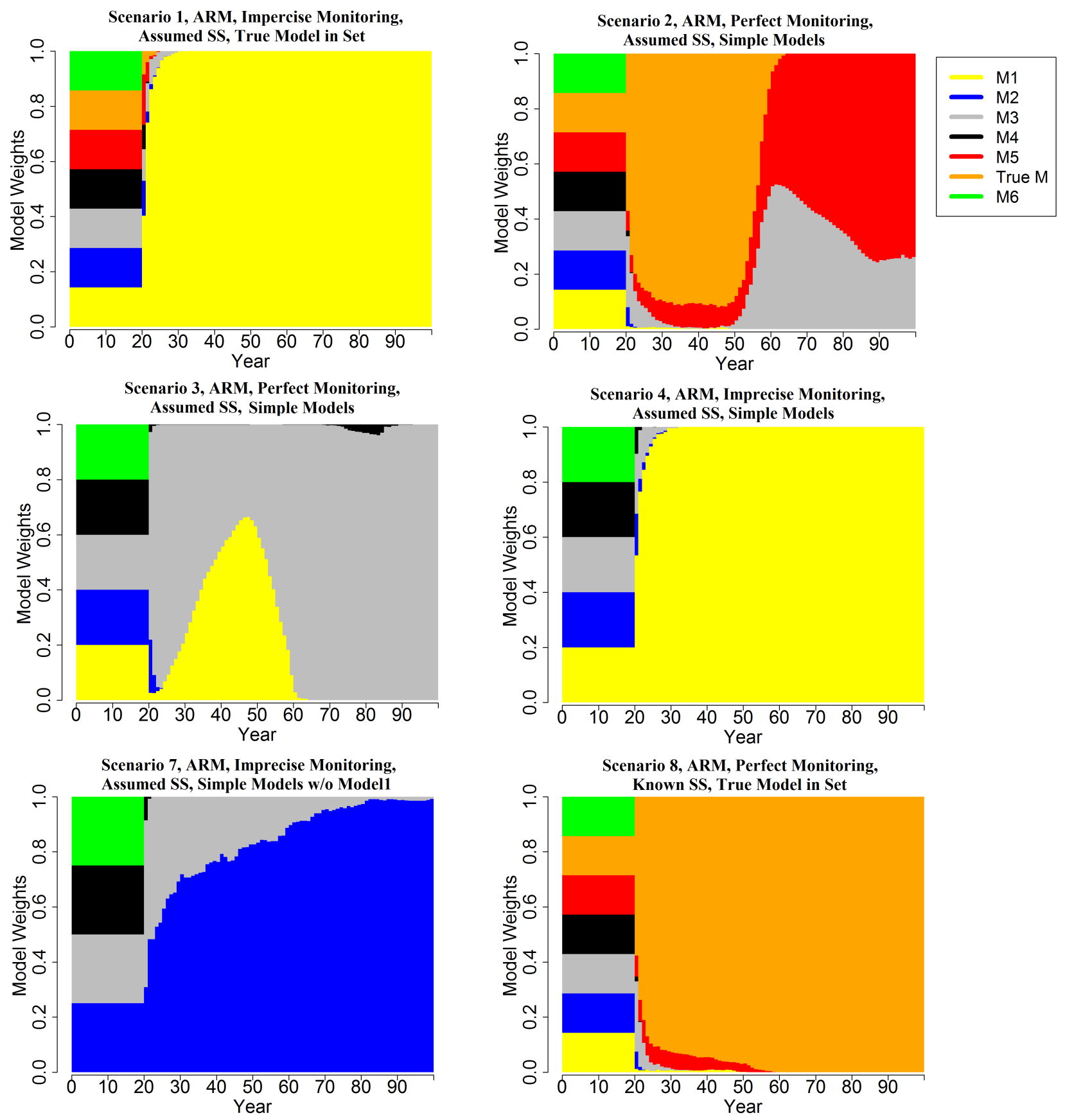

Figure 4 

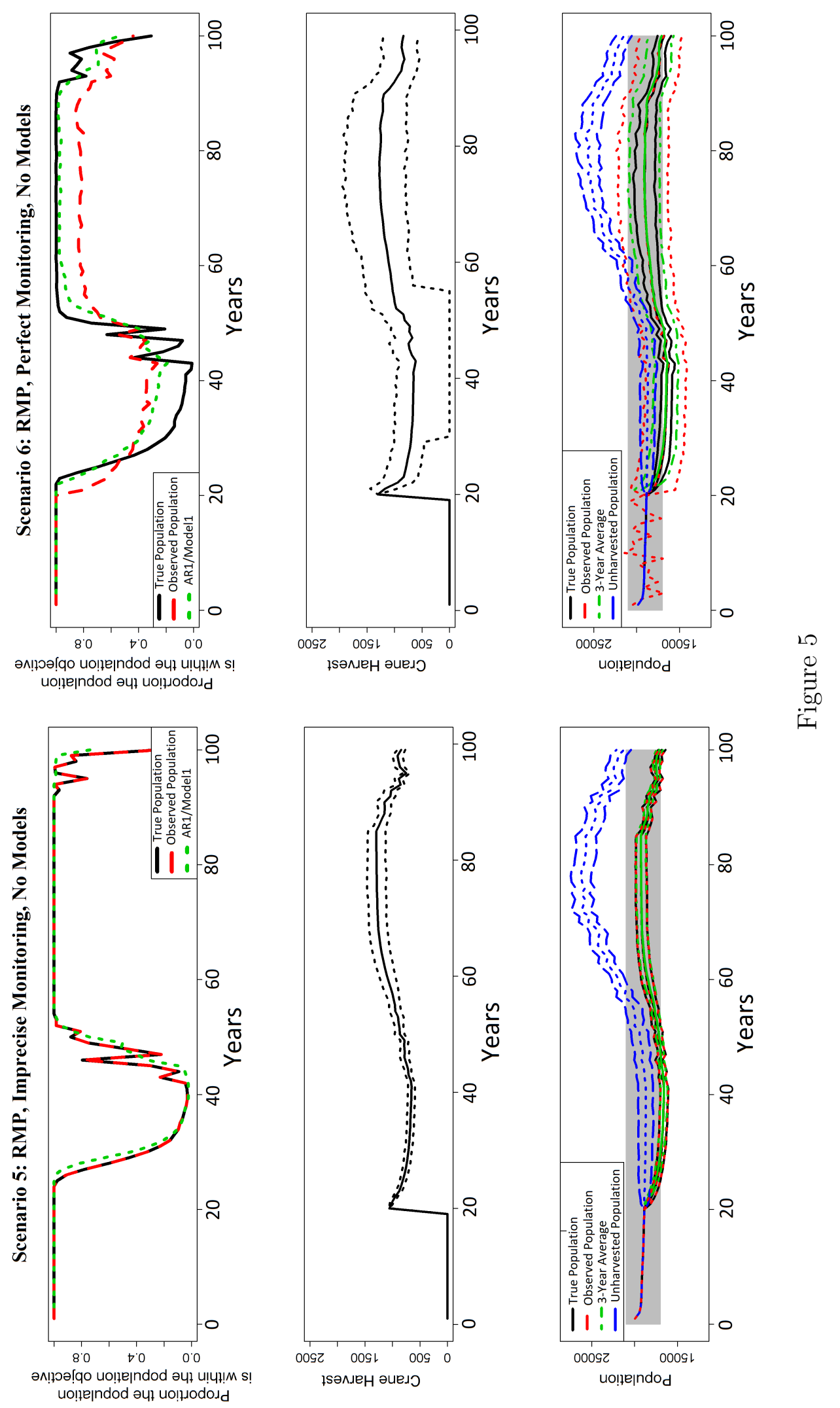